\title{
Determination of nonylphenol ethoxylates in the aquatic environment by normal phase liquid chromatography-electrospray mass spectrometry
}

\author{
Bing Shao ${ }^{\mathrm{a}, \mathrm{b}}$, Jian-ying $\mathrm{Hu}^{\mathrm{b}, *}$, Min Yang ${ }^{\mathrm{a}}$ \\ ${ }^{a}$ State Key Laboratory of Environmental Aquatic Chemistry, Research Center for Eco-Environmental Sciences, \\ Chinese Academy of Sciences, Beijing 100085, China \\ ${ }^{\mathrm{b}}$ Department of Urban and Environmental Science, Peking University, Beijing 100871, China
}

Received 5 July 2001; received in revised form 27 December 2001; accepted 28 December 2001

\begin{abstract}
A comprehensive analytical method based on normal-phase liquid chromatography-electrospray ionization mass spectrometry (NPLC-ESI-MS) has been established for determination of nonylphenol ethoxylates (NPEOs) in the aquatic environment. Extraction and cleanup of samples were performed on graphitized carbon black (GCB) solid-phase extraction cartridges. Complete separation between each individual NPEOs was achieved by combining a $\mathrm{C}_{18}$ pre-column with a silica analytical column and using acetonitrile-water as eluent. Quantitative determination by LC-ESI-MS was achieved in the positive ionization (PI) mode at a ramped cone voltage for NPEOs using selected ion monitoring. Recoveries for NPEOs ranged between 91.9 and $117.5 \%$, and the limits of detection varied between 0.5 and $2 \mathrm{ng} / 1$ for individual NPEOs with $n$ longer than 2, and between 5 and $0.5 \mu \mathrm{g} / 1$ for NP1EO and NP2EO. This method was successfully applied to the investigation of residual NPEOs with $n>2$ in the Chongqing area of the Changjiang river. NPEOs with $n$ ranging from 1 to 22 were found to vary between 0.1 and $2900 \mathrm{ng} / 1$ with a distribution depending on the depth of water. (C) 2002 Elsevier Science B.V. All rights reserved.
\end{abstract}

Keywords: Water analysis; Nonylphenol ethoxylates; Surfactants

\section{Introduction}

Alkylphenol ethoxylates (APEOs) are widely used in households, industry and agriculture. Worldwide, the annual production in 1997 was reported to be in excess of 500 ktons [1], with one-tenth of this produced in China [2]. Among APEOs surfactants,

\footnotetext{
*Corresponding author. Tel.: +86-10-6276-5520; fax: +86-106276-5520.

E-mail address: hujy@urban.pku.edu.cn (J.-y. Hu).
}

NPEOs with average ethylene oxide (EO) units longer than 5 are the most commonly used products, which account for about $80 \%$ of the total market volume. Utilization of NPEOs is under strict regulation in some countries in Europe and North American due to their potential estrogenic effects [3-7].

At present, determination of the distribution of individual NPEOs in the environment has mainly relied on NPLC equipped with a UV, fluorescence (FL) or evaporative light-scattering (ELS) detector [8-10]. NPEOs with $n$ ranging from zero (NP) to 
tens have been successfully separated using this technique. However, the selectivity of the method is insufficient for environmental investigations due to interference from complex matrices. In recent years, LC-MS with an electrospray interface (ESI) has become an important tool in environmental analyses. It can provide information on adduct molecular ions and some fragments, and is applied to analytes with widely different molecular masss and polarities. Some workers have tried to use this technique to establish an NPEOs determination method [11-20]. Pretrovic et al. [12] and Cresenzi et al. [13,16-19] determined total concentrations of NPEOs. Ferguson et al. [14] used selected ion monitoring, and Maruyama et al. [11] used ion intensities in the ESI mass spectrum to quantify individual NPEOs. RPLC with polar eluents such as water-methanol and water-acetonitrile has mainly been used [12-14,1619] to ensure sufficient protonation and deprotonation of analytes in the ESI interface, which resulted in the co-elution of individual NPEOs due to insufficient resolution. Therefore, conventional LC/ ESI/MS can lead to overestimation for low molecular mass NPEOs due to the effect of doubly-charged adducts $[15,20]$. Separation of NPEOs with $n$ ranging from 0 to 19 was achieved by using the normalphase HPLC-MS method [15]. In this case, postcolumn addition of a performing solvent containing sodium acetate $(\mathrm{NaOAc})$ and a split-flow system was applied to enhance protonation of analytes.

In this study, we attempted to establish an analytical method based on NPLC using a reversedphase solvent as eluent coupled to ESI-MS to quantitatively determine individual NPEOs at the trace level. Coupling, optimized separation and applications are reported.

\section{Experimental}

\subsection{Standard solutions and reagents}

Nonylphenol mono-ethoxylate (NP1EO), nonylphenol di-ethoxylates (NP2EO), nonylphenol tri(NP3EO), tetra- (NP4EO), penta- (NP5EO), hexaethoxylates (NP6EO), NP9EO mixture (a mixture of NPEOs with an average of 9 EO units) and NP15EO mixture (a mixture of NPEOs with an average of 15
EO units) were obtained from Hayashi Pure Chemicals (Tokyo, Japan). Standard stock solutions were prepared in methanol. The molar distributions of individual NPEOs in NP9EO were achieved by NPLC-UV at $277 \mathrm{~nm}$ instead of $220 \mathrm{~nm}$, based on the method described below. The compositions of NP9EO were determined using the external standard method assuming that each homologue had the same molar absorption coefficient [21].

Dichloromethane (DCM), acetonitrile, and methanol were HPLC grade (Fisher Chemical Co., China). Ultra pure water was prepared using an Easypure UV Compact Ultrapure System (Fisher Chemical Co., China) under a conductivity of $18.3 \Omega \cdot \mathrm{cm}^{-1}$. Supleclean ENVI-Carb (GCB) solid-phase extraction cartridges $(6 \times 1.4 \mathrm{~cm}$ I.D. polypropylene tubes) were purchased from Supelco (Bellefonte, PA).

\subsection{Sample collection}

Water samples from the Changjiang River in Wanglongmen of the Chongqing area were taken on 28th December 2000. Samples were taken from the surface, the middle layer (10 $\mathrm{m}$ from the surface) and the bottom layer of the river ( $20 \mathrm{~m}$ from the surface), respectively. Water temperature was about $10^{\circ} \mathrm{C}$. The samples were collected in precleaned glass bottles, and $1 \%$ of formaldehyde was added to prevent microbial degradation.

\subsection{Sample preparation}

The procedures used for sample extraction of NPEOs using GCB cartridges have been reported previously [13,16-19] and were used with minor modification. Water samples $(1000 \mathrm{ml})$ were filtered (0.45 $\mu \mathrm{m}$ glass fiber filter paper, Millipore Co., Bedford) and acidified with concentrated $\mathrm{HCl}$. The filter paper was soaked in $100 \mathrm{ml}$ of methanol/water $(50: 50, \mathrm{v} / \mathrm{v})$ solution for $2 \mathrm{~h}$, and then ultrasonicated for $30 \mathrm{~min}$. The resulting solution was mixed with filtrate before extraction. A GCB cartridge was conditioned sequentially with $10 \mathrm{ml}$ of $\mathrm{CH}_{2} \mathrm{Cl}_{2}$ / $\mathrm{CH}_{3} \mathrm{OH}(80: 20, \mathrm{v} / \mathrm{v}), 6 \mathrm{ml} \mathrm{CH} \mathrm{CH}_{3} \mathrm{OH}$, and $6 \mathrm{ml}$ water, $\mathrm{pH}=3$. The acidified water $(\mathrm{pH}=3)$ was passed through the GCB cartridges at $10-15 \mathrm{ml} / \mathrm{min}$, and $100 \mathrm{ml}$ of methanol/water $(50: 50, \mathrm{v} / \mathrm{v})$ used for washing the reservoirs was also passed through the 
cartridge. An additional $10 \mathrm{ml}$ water was applied to wash the cartridge wall. The residual water was removed by passing a gentle nitrogen stream through the cartridges for about $10 \mathrm{~min}$. A total of $10 \mathrm{ml}$ of $\mathrm{DCM} /$ methanol (80:20, v/v) was used as eluent, and passed through the sorbent beds at a rate of 4-5 $\mathrm{ml} / \mathrm{min}$ to desorb NPEOs. The effluents were dried under a gentle nitrogen stream, and reconstituted with $2 \mathrm{ml}$ actonitrile- $\mathrm{H}_{2} \mathrm{O}(95: 5$, v/v) solution containing $5 \mathrm{~m} M \mathrm{NaOAc}$.

To validate the solid-phase extraction method, standard spiking experiments were performed by adding standard solutions to $500 \mathrm{ml}$ lake water from Weiming Lake in Peking University to give final concentrations of NP1EO $10 \mu \mathrm{g} / \mathrm{l}$, NP2EO $20 \mu \mathrm{g} / \mathrm{l}$, NP9EO $5.5 \mu \mathrm{g} / \mathrm{l}$ and NP15EO $5 \mu \mathrm{g} / \mathrm{l}$. Before spiking, blank levels were determined and NPEOs were found to be below detection limits. Triplicate experiments were performed to determine the precision.

\subsection{Liquid chromatography}

Liquid chromatography was performed on an Alliance 2690 HPLC (Waters Corporation, USA) equipped with a quaternary gradient pump, an autosampler with $100 \mu \mathrm{l}$ injection loop, a $\mathrm{C}_{18}$ precolumn (2.1 $\mathrm{mm}$ in ID $\times 50 \mathrm{~mm}$ in length, $3 \mu \mathrm{m}$ Capcell Pak, Shiseido Co., Japan) and a silica analytical column (2.1 $\mathrm{mm}$ in ID $\times 150 \mathrm{~mm}, 3 \mu \mathrm{m}$ Spherisorb SW3, Waters, USA). The flow was kept at $0.1 \mathrm{ml} / \mathrm{min}$ for 1 min with $100 \%$ acetonitrile, then increased linearly to $0.35 \mathrm{ml} / \mathrm{min}$ over $34 \mathrm{~min}$. The solvent composition was changed linearly to $75 \%$-acetonitrile/ $25 \%$-water over $35 \mathrm{~min}$, then linearly to $100 \%$ acetonitrile over $5 \mathrm{~min}$, while the flow was kept at $0.35 \mathrm{ml} / \mathrm{min}$ for $10 \mathrm{~min}$. Flow was then held at 0.1 $\mathrm{ml} / \mathrm{min}$ for $40 \mathrm{~min}$ to equilibrate the columns before the next injection.

\subsection{Mass spectrometry}

A platform ZMD single-quadrupole mass spectrometry (Micromass, Manchester, UK) was used with a Z-Spray ion-source fitted with a pneumatically assisted electro-spray probe. The orthogonal Z-Spray interface allowed the entire column effluent from the LC to be directed into the source without flow splitting, which contributed to the greatly enhanced sensitivity. In the positive mode, typical ion source parameters were used as follows: ESI capillary voltage at $3.5 \mathrm{kV}$; extractor voltage at $5 \mathrm{~V}$; source block temperature at $120^{\circ} \mathrm{C}$; desolvation temperature at $180{ }^{\circ} \mathrm{C}$; ion energy at $0.8 \mathrm{~V}$; multiplier voltage at $650 \mathrm{~V}$. Nitrogen was used as the desolvation gas with a flow-rate between 270 and $350 \mathrm{l} / \mathrm{h}$ and cone gas with a rate of $70-1001 / \mathrm{h}$; the cone voltage was ramped from 25 to $70 \mathrm{~V}$ with the full scan mass ranging from 280 to 1500 dalton with a scan time of $1.2 \mathrm{~s}$.

\subsection{Qualification and quantitation}

The qualitative identification of a target compound was done in a full-scan mode by matching the retention time and the mass spectrum with standards. Quantitative analysis was performed using selected ion monitoring in order to achieve maximum sensitivity. A series of five standard solutions was prepared by diluting the standard stock solution with $5 \mathrm{~m} M \mathrm{NaOAc}$ acetonitrile/ $\mathrm{H}_{2} \mathrm{O}(95: 5, \mathrm{v} / \mathrm{v})$ solution. The total concentrations of NP9EO in these solutions were $0.14,0.56,2.3,4.6,9.2 \mathrm{mg} / 1$. Five-point calibration curves for individual NPEOs with $n>6$ were obtained by triplicate injections of standard solution. For NPEOs with $n$ ranging from 1 to 6 , five point calibration curves were also constructed by injections of their pure standard compounds. For real samples, the concentrations were achieved through the extracts concentration divided concentration times and recovery rate.

Lowest instrument quantitative detection limits $\left(\mathrm{LOD}_{\text {inst }}\right)$ were evaluated by a signal-to-noise of 10 in SIM mode. The method lowest detection limits $\left(\mathrm{LOD}_{\text {meth }}\right)$ were obtained by correcting $\mathrm{LOD}_{\text {inst }}$ with the recoveries of target compounds and volume of sample.

\section{Results and discussion}

\subsection{Chromatography}

Fig. 1(A) shows the total ion current chromatogram of a mixture in acetonitrile solution containing $10.5 \mathrm{mg} / 1 \mathrm{NP} 2 \mathrm{EO}, 1 \mathrm{mg} / 1 \mathrm{NP} 9 \mathrm{EO}$, and $1 \mathrm{mg} / \mathrm{l}$ 

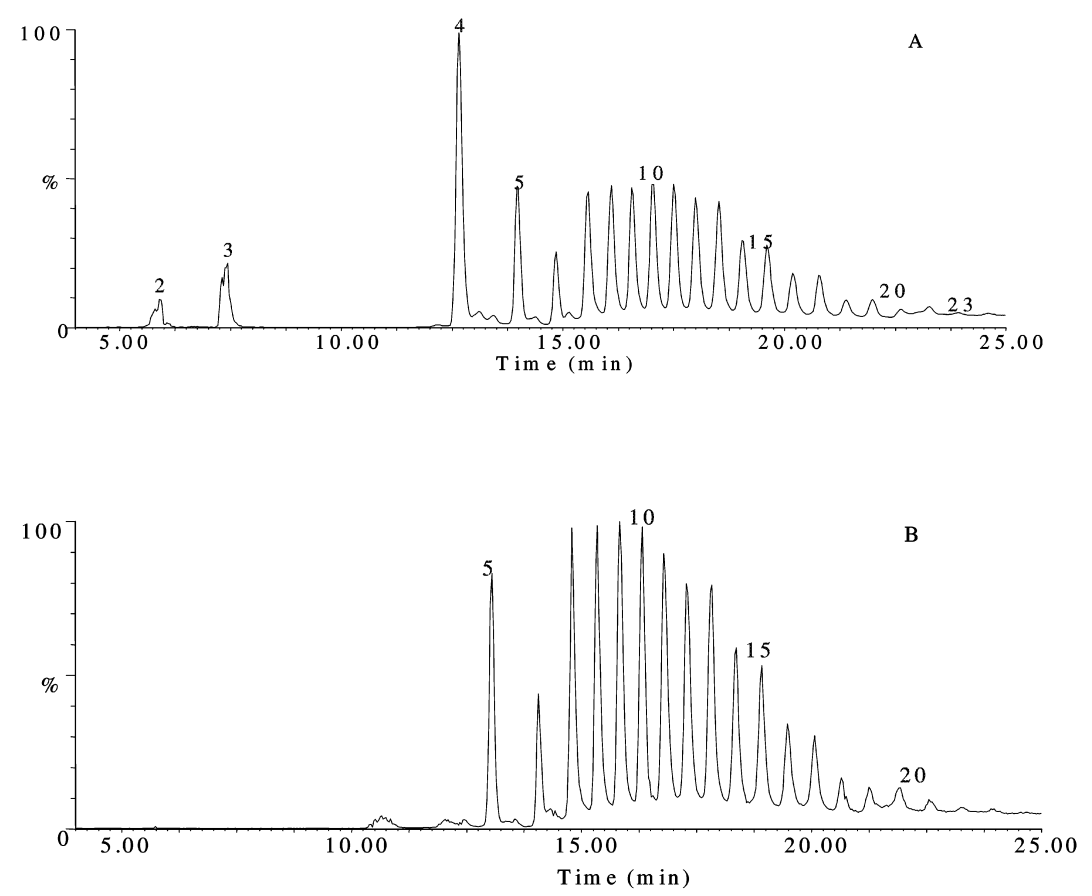

Fig. 1. LC-ESI-MS (PI) chromatograms of mixtures containing NP2EO (10.5 mg/1), NP9EO (1 mg/l) and NP15EO (1 mg/l). (A) Standard mixture of acetonitrile solution, separated using $\mathrm{C}_{18}$ precolumn. (B) Standard mixture of acetonitrile solution, separated without $\mathrm{C}_{18}$ precolumn. Numbers above peaks correspond to the number of EO units in each separated component.

NP15EO with an injection volume of $20 \mu l$. As shown in the chromatogram, individual NPEOs with a wide range of ethoxylated components $(n=2-25)$ could be completely separated. In addition, the effects of separation were found to be satisfactory even when the injection volume was increased to 80 $\mu l$. No peak of NP1EO, however, was seen for its low sensitivity in our experimental condition.

Fig. 1(B) shows the TIC chromatogram of the mixture in acetonitrile solution without the hydrophobic ODS $\left(\mathrm{C}_{18}\right)$ precolumn. Comparison with Fig. (A) revealed that while the complete separation of individual NPEOs with $n$ from 5 to 25 was achieved, no peaks for NPEOs with short EO chain lengths of $n<5$ were found in the chromatogram. It is apparent that NPEOs with short EO chain lengths of $n<5$ could not be separated without the precolumn. The above results suggest the importance of the hydrophobic $\mathrm{C}_{18}$ precolumn for retaining and separating the NPEOs of low EO values $(n<5)$. To confirm the above fact, a further investigation using $\mathrm{C}_{18}$ precolumn was conducted to separate the pure acetoni- trile solutions of these compounds. It was found that the peak of target compounds was separated with that of acetonitrile when gradient described in experimental section was used (Fig. 2).

It is well known that silica-based materials tend to bind water. In this experiment, a change in retention time of NPEOs, especially for the short EO unit NPEOs $(n<5)$ was observed as shown in Fig. 3 after the column had been successively used for 3 months. The performance of the column, however, could be recovered completely through equilibration with

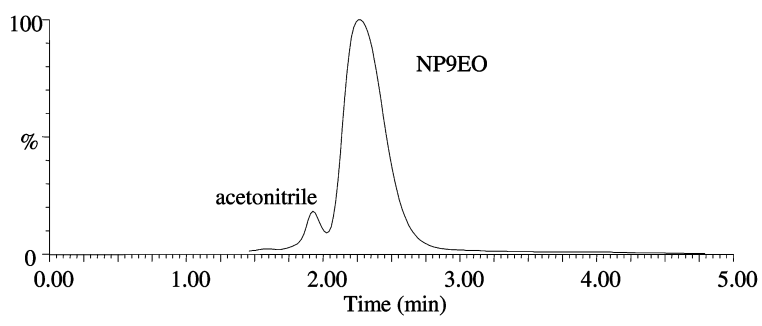

Fig. 2. Chromatogram of NP9EO (2 mg/l) obtained with an UV detector. 


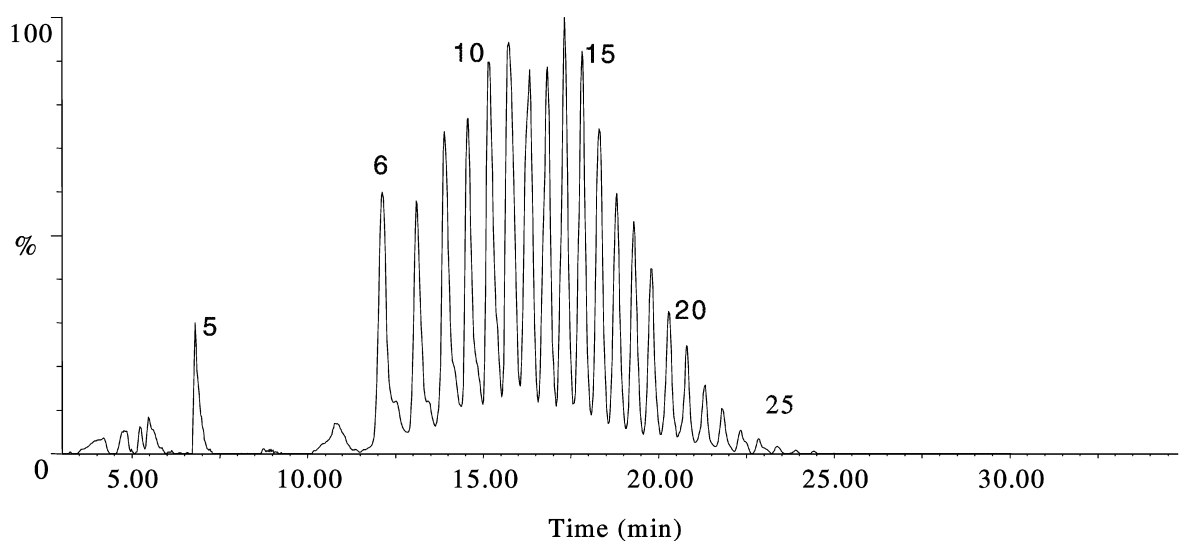

Fig. 3. LC-ESI-MS (PI) chromatogram of mixtures containing NP9EO (1 mg/1) and NP15EO 1.2 (mg/l), obtained with the column, which had been in use for 3 months.

$100 \%$ acetonitrile. An equilibration time of $40 \mathrm{~min}$ with $100 \%$ acetonitrile was sufficient to assure the regeneration of the silica column. When the equilibration time was shorter than $40 \mathrm{~min}$, the retention time for NPEOs with $n<6$ tended to drift easily.

\subsection{Mass spectrometry}

Ubiquitous ions such as $\mathrm{Na}^{+}, \mathrm{K}^{+}, \mathrm{NH}_{4}^{+}$can make it difficult for quantification of NPEOs because of the uncertainness of distribution of ion adducts [15]. In some studies, $\mathrm{NaOAc}$, ammonium acetate or potassium acetate have been added to the extracts of samples prior to injection, or spiked directly into eluents to provide sufficient metal ions $[11,14,15]$. In this paper, the performance of different sodium salt (NaOAc) spiking methods was assessed and compared. It was found that the relative standard deviations (RSD) of different spiking methods was under $20 \%$ for real samples (results not shown). For standard samples, however, NP1EO, NP2EO and NP3EO could not be ionized when NaOAc was added only to eluents, while a relatively high sensitivity for NP2EO and NP3EO was achieved when $\mathrm{NaOAc}$ was spiked to standard samples at a concentration level of $5 \mathrm{mM}$ and kept for $48 \mathrm{~h}$. The results suggest that a period of equilibration time was needed for the bind between $\mathrm{Na}^{+}$with NPEOs $(n<$ 4) as described in previous report [15]. An attempt to identify whether the property of organic phase of eluents can affect the adduction of NPEOs with $\mathrm{Na}^{+}$ was also performed. It was found that methanol significantly promoted the ionization of the NP1EO, NP2EO and NP3EO. However, the eluents upon using methanol and water was failed to separate all NPEOs based on their EO units. Therefore, the method of spiking $\mathrm{NaOAc}$ directly to samples was adopted in this study.

In this study, doubly charged adducts were also often found in the mass spectrum of NPEOs as described in other articles [15]. Fig. 4(A) is the mass spectrum of NP19EO at retention time $22.34 \mathrm{~min}$ in standard mixtures using a stable cone voltage of 30 $\mathrm{V}$ (chromatogram not shown). In this spectrum, a doubly charged adduct $\left(\mathrm{NP} 19 \mathrm{EO}+2 \mathrm{Na}^{+}\right)$of $\mathrm{m} / \mathrm{z}$ 551.3 was the base ion. The relative intensity of the $\mathrm{Na}^{+}$adducted molecular ion (NP19EO $+\mathrm{Na}^{+}$), however, was as low as $20 \%$. It should be noted that the $\mathrm{Na}^{+}$adducted molecular ion of NP7EO also appears at $m / z 551.3$, so the concentration of NP7EO might be overestimated if NPEOs cannot be separated as individual components.

Fig. 4(B) shows the mass spectrum of NP19EO of the same sample obtained under a ramped voltage. The corresponding cone voltage was $60 \mathrm{~V}$. Under these conditions, the molecular ion (NP19EO $+\mathrm{Na}^{+}$) related to structural information became the base ion at $\mathrm{m} / \mathrm{z}$ 1079.8, and the relative intensity of $\mathrm{NP} 19 \mathrm{EO}+2 \mathrm{Na}^{+}(\mathrm{m} / z$ 551.3) was only $50 \%$. In real samples, although the doubly charged ion cannot be avoided even by changing the cone voltage, the 

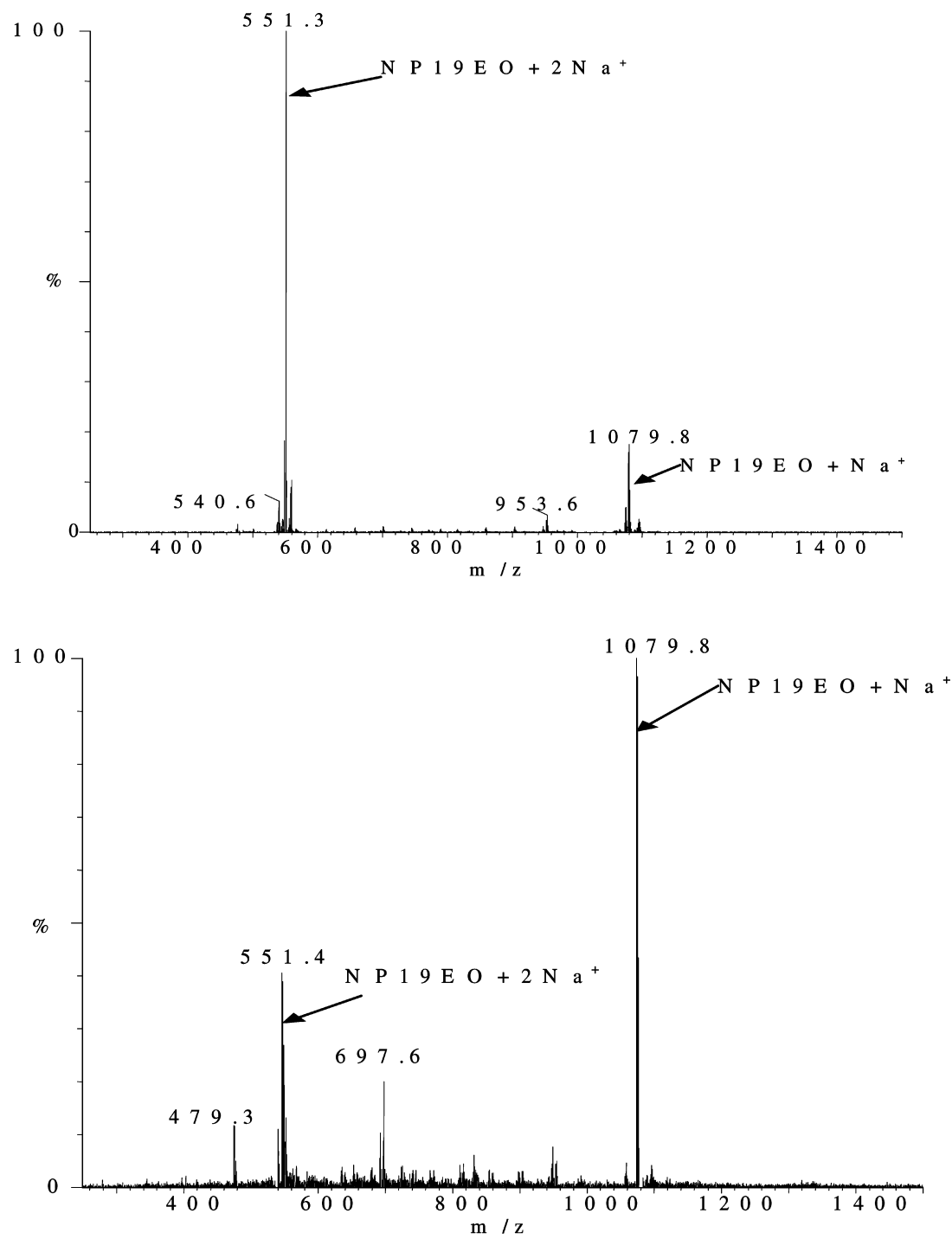

Fig. 4. LC-ESI-MS (PI) mass spectrums of NP19EO $+\mathrm{Na}^{+}$(A) using cone voltage $30 \mathrm{~V}$; (B) using ramped cone voltage with retention time of $22.34 \mathrm{~min}$.

formation of doubly charged adducts can effectively be suppressed by setting suitable ionization conditions. This is helpful in identification of NPEOs with a relatively high molecular mass and makes it possible to determinate the EO chain distribution accurately. Thus overestimation can be avoided by using the NPLC-MS method developed in this paper.

\subsection{Method validation}

The average recoveries of individual NPEOs in environmental samples are listed in Table 1. For all the objective analytes, the recoveries of NPEOs with $n$ from 1 to 24 were achieved in the range from 92 to $117 \%$, most being between 98 and 105\%. Moreover, the samples used in spiking experiment contained 
Table 1

Mean recoveries, repeatability (RSD for $N=3$ ) and absolute limits of detection (LODs) obtained in selected ion monitoring (SIM) mode (in parentheses, $5 \mu$ l injection)

\begin{tabular}{|c|c|c|c|c|c|}
\hline & Mean recoveries \pm RSD & & Mean recoveries \pm RSD & & Mean recoveries \pm RSD \\
\hline NP1EO & $93 \pm 15(25 \mathrm{ng})$ & NP9EO & $100 \pm 6$ & NP17EO & $105 \pm 15$ \\
\hline NP2EO & $102 \pm 3(2.5 \mathrm{ng})$ & NP10EO & $102 \pm 8$ & NP18EO & $103 \pm 12$ \\
\hline NP3EO & $93 \pm 10(1 \mathrm{pg})$ & NP11EO & $101 \pm 2$ & NP19EO & $106 \pm 10$ \\
\hline NP4EO & $94 \pm 8(0.5 \mathrm{pg})$ & NP12EO & $99 \pm 5$ & NP20EO & $102 \pm 16$ \\
\hline NP5EO & $97 \pm 20(0.2 \mathrm{pg})$ & NP13EO & $99 \pm 5$ & NP21EO & $102 \pm 18$ \\
\hline NP6EO & $97 \pm 6(0.2 \mathrm{pg})$ & NP14EO & $117 \pm 8$ & NP22EO & $105 \pm 15$ \\
\hline NP7EO & $105 \pm 20$ & NP15EO & $112 \pm 16$ & NP23EO & $103 \pm 11$ \\
\hline NP8EO & $101 \pm 9$ & NP16EO & $108 \pm 13$ & & \\
\hline
\end{tabular}

more humus and higher suspending particles than those in samples taken from Changjiang River. This indicates that the method performed satisfactorily despite interference by environmental matrices. Relative standard deviations (RSDs) of the triplicate analysis of spiked samples ranged from 2.3 to $20 \%$. The between-day reproducibility of environmental sample was determined with triplicate detection over 5 days and the RDS for all of NPEOs were below $20 \%$.

Lowest instrument quantitative detection limits are estimated to be $25 \mathrm{ng}, 2.5 \mathrm{ng}$, and $0.2-1 \mathrm{pg}$ for NP1EO, NP2EO, NPEOs $(n>2)$, respectively, when the injection volume is $5 \mathrm{ml}$. The detection limits of individual NPEOs with $n>2$ are an significant improvement over previous reported mass sensitivities for NPLC-ESI-MS (1-4 ng) [15], nearly two order of magnitudes lower than that of reversedphase LC-ESI-MS analysis of NPEOs (2.5 ng) [12], and about two to three magnitudes lower than that of NPLC-FL analysis of individual NPEOs (0.2 ng) [9]. Considering the concentration times and recoveries of individual NPEOs, the detection limits of this method were estimated to be $5 \mu \mathrm{g} / 1,0.5 \mu \mathrm{g} / 1,2$, $1,0.5 \mathrm{ng} / 1$ for NP1EO, NP2EO, NP3EO, NP4EO and NPEOs $(n>4)$, respectively. Over the established ranges $(0.5-46 \mathrm{ng})$ linear regression analysis of individual NPEOs concentration vs. peak area gave good fits $\left(r^{2}>0.97\right)$ for each NPEOs.

\subsection{Method application to river water}

NPLC ESI-MS established in this study was applied to analyze the residual NPEOs in environ- mental water. Three samples respectively taken from river surface, middle layer $(10 \mathrm{~m})$ and bottom layer $(20 \mathrm{~m})$ of the Changiang River in the Chongqing area were analyzed to investigate the distribution of the target components relative to the depth of river. Fig. 5 shows the chromatogram of the extracts from the bottom sample. NPEOs with $n$ from 3 to 19 were found in bottom water.

NP1EO and NP2EO could not be detected by NPLC-ESI-MS because the method developed in this study has a relatively low sensitivity for the two NPEOs. This is not a problem, however, because GC-MS can be used for determination of the two with a very high sensitivity. Determination of NP1EO and NP2EO was conducted by a GC-MS method [22], and it was found that the two components were only found in the sample of surface water with a concentration of 0.08 and $0.04 \mu \mathrm{g} / \mathrm{l}$, respectively. By the use of GC-MS, NPEOs with n ranging from 1 to 22 were found to vary between 1 and $2900 \mathrm{ng} / \mathrm{l}$ depending on the depth of water. The results also suggested that NPEOs increased with water depth, and that the concentrations in the bottom layer were significantly higher than those in the upper layer. Further investigation in this area is performing to probe into the reasons.

\section{Conclusions}

An NPLC-ESI-MS method with satisfactory sensitivity, selectivity, and reproducibility was established for environmental investigation of NPEOs with $n>2$. This technique surmounts the shortcom- 


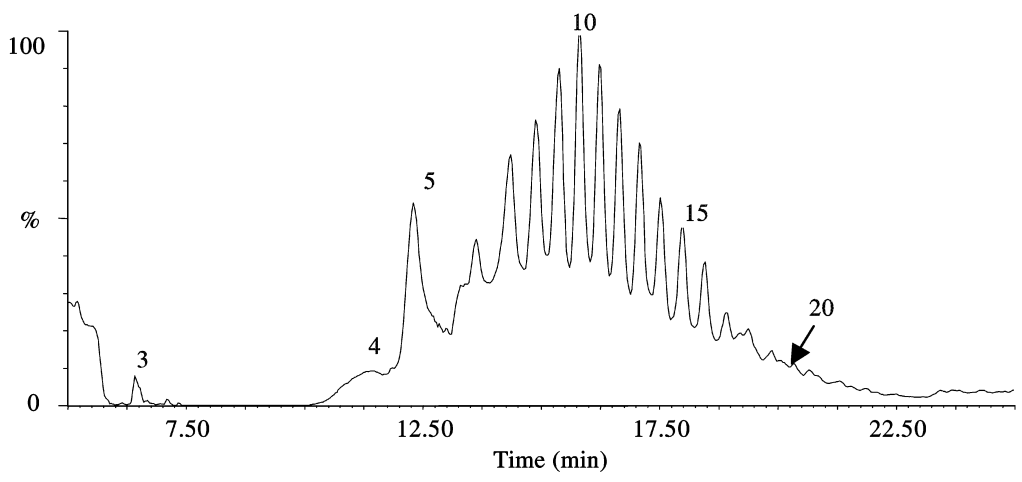

Fig. 5. LC-ESI-MS (PI) chromatogram of extract of bottom layer water of Wanglongmen.

ings of the conventional methods such as NPLC-UV, NPLC-FL and reversed-phase LC-ESI-MS, and can be used for the accurate evaluation of pollution by NPEOs. This method uses ramped cone voltage, which suppressed appearance of doubly charged adducts effectively and increased the response of oligomers of relatively high polymeration degree. A limitation of this method is the relatively high detection limits for NP1EO and NP2EO, for which the method could be substituted by GC-MS or LC-FL.

\section{Acknowledgements}

Financial support from the National Natural Science Foundation of China [49925103 and 40024101] is gratefully acknowledged.

\section{References}

[1] C.G. Naylor, Proceedings of the CESIO 4th World Surfactants Congress, Barcelona, Spain; European Committee on Surfactants and Detergents; Brussels, Belgium, 1996, p. 378.

[2] H.Z. Huang, Handbook of Chemical Products: Industrial Surfactants, Chemical Industry Press, Beijing, 1998.

[3] R. White, S. Jobling, S.A. Hoare, J.P. Sumpter, M.G. Parker, Endocrinology 135 (1994) 175.
[4] R.M. Sharpe, J.S. Fisher, M.M. Millar, S. Jobling, J.P. Sumpter, Environ. Health Perspect. 103 (1995) 1136.

[5] S. Jobling, D. Sheahan, J.A. Osborn, P. Matthiessen, J.P. Sumpter, Environ. Toxicol. Chem. 15 (1996) 194.

[6] M.R. Servos, Water Qual. Res. J. Canada 34 (1999) 123.

[7] Y. Nakamura, J. Jpn. Soc. Water Environ. 21 (1998) 192.

[8] M. Ahel, W. Giger, Anal. Chem. 57 (1985) 2584.

[9] M.S. Holt, E.H. McKerrel, J. Perry, R.J. Watkinson, J. Chromatogr. 362 (1986) 419.

[10] T.C.G. Kibbey, T.P. Yavaraski, K.F. Hayes, J. Chromatogr. A 752 (1996) 155

[11] K. Maruyama, M. Yuan, A. Otsuki, Environ. Sci. Technol. 34 (2000) 343.

[12] M. Pretrović, D. Barceló, Anal. Chem. 72 (2000) 4560.

[13] C. Cresenzi, A. Di Corcia, R. Samperi, Anal. Chem. 67 (1995) 1797.

[14] P.L. Ferguson, R.I. Charles, B.J. Brownawell, Anal. Chem. 72 (2000) 4322

[15] D.Y. Shang, M.G. Ikonomou, R.W. MacDonald, J. Chromatogr. A 849 (1999) 467.

[16] A. Di Corcia, A. Costantino, C. Crescenzi, E. Marinoni, R. Samperi, Environ. Sci. Technol. 32 (1998) 2401.

[17] A. Di Corcia, R. Cavallo, C. Crescenzi, M. Nazzari, Environ. Sci. Technol. 34 (2000) 2401.

[18] A. Di Corcia, R. Samperi, A. Macromini, E. Marinoni, Environ. Sci. Technol. 28 (1994) 850.

[19] N. Jokers, T.P. Knepper, P. De Voogr, Environ. Sci. Technol. 35 (2001) 335.

[20] D.Y. Shang, R.W. MacDonald, M.G. Ikonomou, Environ. Sci. Technol. 33 (1999) 1366.

[21] Z. Wang, M. Fingas, J. Chromatogr. A 673 (1993) 145.

[22] B. Shao, J.Y. Hu, M. Yang, Acta Environ. Sci. 22 (2002) 12. 